\title{
Real-Time Measurement of Rates of Outdoor Airflow into HVAC Systems: A Field Study of Three Technologies
}

\author{
William J. Fisk, Douglas P. Sullivan, David Faulkner \\ Environmental Energy Technologies Division \\ Indoor Environment Department \\ Lawrence Berkeley National Laboratory \\ Berkeley, CA 94720
}

September 16, 2005

This work was supported by the Assistant Secretary for Energy Efficiency and Renewable Energy, Building Technologies Program of the U.S. Department of Energy under contract DEAC02-05CH11231. 


\title{
Real-Time Measurement of Rates of Outdoor Airflow into HVAC Systems: A Field Study of Three Technologies
}

\author{
William J. Fisk, Douglas P. Sullivan, David Faulkner \\ Environmental Energy Technologies Division \\ Indoor Environment Department \\ Lawrence Berkeley National Laboratory \\ Berkeley, CA 94720
}

September 16, 2005

\section{ACKNOWLEDGEMENTS}

This work was supported by the assistant Secretary for Energy Efficiency and Renewable Energy, Building Technologies Program of the U.S. Department of Energy under contract DE-AC02-05CH11231. The authors thank Terry Logee of DOE for program management and Steve Taylor and Peng Xu for their reviews of a draft of the report on which this paper was based. 
LBNL 58856

\title{
REAL-TIME MEASUREMENT OF RATES OF OUTDOOR AIRFLOW INTO HVAC SYSTEMS: A FIELD STUDY OF THREE TECHNOLOGIES
}

\begin{abstract}
Technologies for real-time continuous measurement of the flow rates of outdoor air (OA) into HVAC systems are now available commercially. Our prior papers reported on laboratory-based evaluations of these measurement technologies and this document describes the methods and results of a field study of the accuracy of three of these technologies. From the field study data, we determined that neither wind speed nor wind direction have an important adverse impact on measurement accuracy. The field study confirmed that these three measurement technologies can provide reasonably accurate measurements of outdoor air intake rates in field settings, if the pressure signals are measured with high accuracy. Some of the pressure transducers marketed for use with commercial HVAC systems were determined to be sufficiently accurate for this application. Given the significant impact of OA flow rates on both energy use and occupant health, more widespread use of technologies that provide for real time measurements of OA flow rates seems warranted.
\end{abstract}

\section{BACKGROUND}

Ventilation, i.e., providing outdoor air (OA), has a substantial influence on building energy consumption, occupant health, and occupant satisfaction with the indoor environment. We have estimated (Fisk et al. 2005a) that approximately 1 Quad (1 EJ) of energy is used annually in the U.S. to thermally condition the outdoor air supplied to service sector buildings. We have also estimated (Fisk et al. (2005a) that approximately 0.3 Quad (0.3 EJ) of energy would be saved annually if the average minimum rate of OA supply was reduced to bring rates in alignment with the current standards.

The "correct" minimum rate of outdoor air supply to maintain occupant health and satisfaction with air quality is not well known. The minimum rate for offices in the ASHRAE ventilation standard (ASHRAE 1999) was, until recently, $20 \mathrm{cfm}(10 \mathrm{~L} / \mathrm{s})$ per occupant. The current ventilation standard (ASHRAE 2004) has a minimum ventilation requirement per person and per unit floor area that, with typical occupant density and ventilation efficiency assumptions, translates into approximately the same per person requirement as the older standard. The scientific literature on the relationships of ventilation rates with health and occupant satisfaction was reviewed by Seppanen et al. (1999). On average, lower ventilation rates were associated with increased prevalence of communicable respiratory illnesses (e.g., common colds), increased prevalence rates of sick building syndrome (SBS) symptoms, and diminished satisfaction with indoor air quality. The evidence of adverse effects was strongest when ventilation rates were reduced below $20 \mathrm{cfm}\left(10 \mathrm{~L} \mathrm{~s}^{-1}\right)$ per person; however, several studies reported benefits of increasing ventilation rates above $20 \mathrm{cfm}\left(10 \mathrm{~L} \mathrm{~s}^{-1}\right)$ per person. Clearly, there is a need to strike a balance between the potential benefits to health of increased ventilation and the beneficial energy savings from reduced ventilation.

Despite the substantial influences of OA ventilation rates on energy use and health, most U.S. buildings do not have an integral system for measuring ventilation rates. The typical practice in office and institutional buildings, which are the primary focus of this report, is to have an air balance company measure the OA flow during building commissioning or airflow balancing and adjust the positions of the dampers for OA, recirculation air, and exhaust air to obtain the desired minimum rate of OA supply. However, accurately measuring OA airflow into HVAC systems is technically very challenging (Fisk et al. 2005a, 2005b; Kettler 1995, 2000; Krarti et al. 1999). Given the measurement challenges and the 
presence of significant infiltration in many buildings, it is not surprising that the ventilation rates measured in surveys by researchers using tracer gas based measurement systems or other methods (e.g., Turk et al. 1987, Lagus Applied Technologies 1995, Persily 1989, Persily and Gorfain 2004) vary widely and often differ substantially from the minimum ventilation rates ${ }^{1}$ specified in the applicable codes and in design documents.

Because the available data indicate that most buildings have minimum ventilation rates substantially exceeding code requirements, routine use of OA measurement systems that enable better control of minimum OA supply may be a cost-effective method of reducing energy use in over ventilated buildings. A significant but smaller fraction of buildings provide less ventilation than specified in codes, and OA measurement systems in these buildings could reduce IAQ problems from insufficient ventilation.

In prior papers, Fisk et al. (2004, 2005b) summarized the results of laboratory-based studies of some of these technologies. The laboratory studies identified three technologies that should provide reasonably, e.g., 20\%, accurate measurements of OA flow rates as long as air velocities are maintained high enough to produce accurately measurable pressure signals. When these three technologies are used in HVAC systems with economizer controls, to maintain measurement accuracy the OA intake will need to be divided into two sections in parallel, each with a separate OA damper. All three of the measurement devices had pressure drops that are likely to be judged acceptable. In another paper, some of the causes and potential cures for measurement errors were documented (Fisk et al 2005b).

One of the limitations of the prior studies of these measurement technologies was that they took place in the laboratory, while in real field settings the intake air is drawn from an outdoor location subject to wind, variable temperatures, rainfall, other conditions that do not occur in laboratories. When we used fans in the laboratory to cause a high velocity at the outdoor air intake louvers, there was evidence of reduced measurement accuracy (Fisk et al. 2003). We hypothesized that winds could reduce measurement accuracy by changing the velocity profile of the OA flowing through an OA intake louver and through the system of velocity sensors located downstream of the louver. However, in the laboratory we were unable to accurately reproduce real winds; thus, we could not provide reliable tests of the extent to which winds affect measurement accuracy. Another limitation of our laboratory studies was that they employed a highly accurate research-grade pressure transducer in conjunction with the measurement technologies, while, in real buildings less expensive and, presumably, less accurate pressure transducers will normally be used. Consequently, the present study was designed to test three technologies for measuring OA intake flow rates in a controlled field setting with the outdoor air intake louver subject to real winds that varied in speed and direction. In addition, the present study assessed how the accuracy of measurements of OA flow rates will be influenced by the pressure measurement errors of pressure transducers typical of those used in building HVAC systems.

\section{APPROACH}

\section{Measurement Technologies Evaluated}

This paper summarizes results of our evaluations of three OA measurement technologies. In all cases, the overall cross sectional dimensions of the OA inlet section was $2 \mathrm{ft}$ by $2 \mathrm{ft}(0.6 \mathrm{~m}$ by $0.6 \mathrm{~m})$.

Measurement technology number 1 (MT1), illustrated in Figure 1, integrates a set of closely spaced (1.5 inch [3.8 cm]) vertical louver blades with a set of downstream airflow sensing blades that extend over the height of the louver system and that are centered between adjacent blades of the louver. The manufacturer provides a calibration curve in terms of average air velocity through the free-area of the louver system versus pressure signal from the airflow sensing blades. The airflow sensing blades appear to be designed to provide a pressure signal proportional to the average velocity along a vertical path

\footnotetext{
${ }^{1}$ The codes specify minimum ventilation rates that are usually interpreted as minimum rates of outdoor air intake through HVAC systems.
} 
centered between adjacent louvers, where the average velocity exceeds that in the duct downstream of the louver. Compared to many louver systems, the MT1 louver system also has a relatively high recommended maximum free area velocity which helps to maintain a measurable pressure signal.

The manufacturer's minimum "velocity requirement" for MT1 was $345 \mathrm{fpm}\left(1.8 \mathrm{~m} \mathrm{~s}^{-1}\right)$ in the free area of the louver. The corresponding OA flow is $430 \mathrm{cfm}\left(0.20 \mathrm{~m}^{3} \mathrm{~s}^{-1}\right)$. Manufacturer's data indicate that the pressure drop across the louver system (without a bird screen) ranges nonlinearly from 0.01 inch water $(2.5 \mathrm{~Pa})$ with an air velocity through the free area of $470 \mathrm{fpm}\left(2.4 \mathrm{~m} \mathrm{~s}^{-1}\right)$ to 3 inch water $(747 \mathrm{~Pa})$ with a velocity of $7300 \mathrm{fpm}\left(37 \mathrm{~m} \mathrm{~s}^{-1}\right)$. MT1 was installed with the face of the louver flush with the wall of the building. The nearest downstream component was an OA damper located $1 \mathrm{ft}(0.30 \mathrm{~m})$, downstream of the downstream face of MT1.

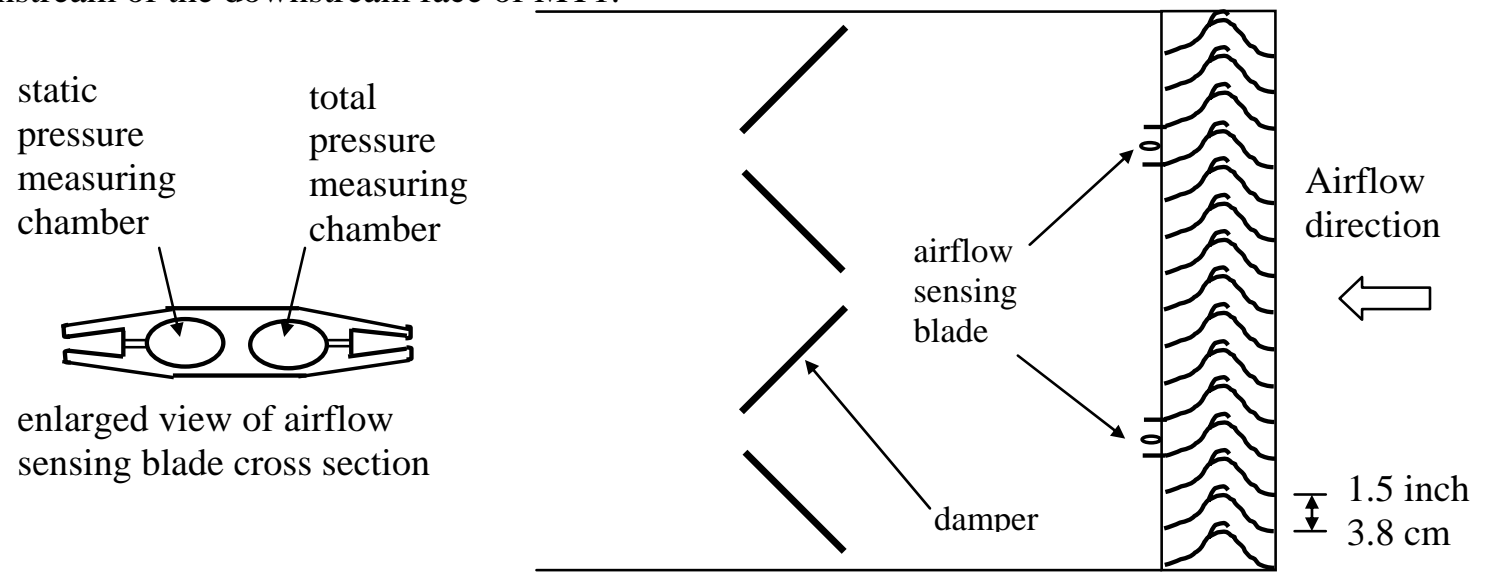

Figure 1. Illustration of outdoor airflow measurement technology number 1 (MT1), consisting of the OA intake louver and integral airflow sensing blades, shown installed at the inlet of a HVAC system. Top views of cross section of the louvers and airflow sensing blades are shown. The airflow sensing blades extend vertically nearly the full height of the louver system.

In this field study, we did not evaluate a measurement technology, called MT2, from our prior laboratory studies (Fisk et al. 2004). To maintain our numbering system, the next technology described in this paper is designated Measurement Technology 3 (MT3), which is illustrated in Figure 2. MT3 uses a special static pressure tap at the outdoor face of the OA inlet and another type of static pressure tap downstream of the OA louver to sense the pressure drop across the louver. The outdoor pressure tap was mounted flush with the outdoor face of the OA intake louver and 2 in $(5 \mathrm{~cm})$ horizontally from the edge of the louver so that it did not block and airflow into the louver. This tap appears to be designed to provide a pressure signal unaffected by wind direction. The pressure tap placed downstream of the louver, called an "inlet airflow sensor" was a 0.5 inch $(1.3 \mathrm{~cm})$ diameter 5 inch $(13 \mathrm{~cm})$ long cylinder with a 0.8 inch $(2 \mathrm{~cm})$ long sintered metal end that is inserted through a duct wall into the airstream. We presume that this tap is designed to provide a reliable measure of static pressure in the turbulent airstream located downstream of a louver. For tests of MT3 using louver 1 (louvers are described subsequently), we installed this inlet airflow sensor 6 inch $(15 \mathrm{~cm})$ downstream of the downstream face of the louver 1 and 6 inch $(15 \mathrm{~cm})$ upstream of the inlet face of the OA damper ${ }^{2}$. For tests of MT3 using louver 3, this inlet airflow sensor was 4 inch $(10 \mathrm{~cm})$ downstream of the downstream face of the louver and 4 inch $(10$ $\mathrm{cm}$ ) upstream of the inlet of MT4, which is described subsequently. The full MT3 system comes with a pressure transducer, temperature sensor to enable control for air density, electronics, and a digital display. The system is designed for OA velocity ranges of either 150 to $600 \mathrm{fpm}\left(0.8\right.$ to $\left.3.0 \mathrm{~m} \mathrm{~s}^{-1}\right)$ or 250 to 1000 fpm (1.3 to $\left.5.1 \mathrm{~m} \mathrm{~s}^{-1}\right)$ and has a rated accuracy of $\pm 5 \%$ of the reading. The relationship of measured pressure drop to OA flow rate will vary with the design of the louver and must therefore be determined

\footnotetext{
${ }^{2}$ Results from other test conditions are provided in Fisk et al. (2005a).
} 
via a factory or field-based determination of this relationship. We did not use the manufacturer's electronics or pressure sensor -- we used our research grade pressure transducer and other pressure transducers to measure the pressure difference. Thus, our tests only determined whether the OA flow rate could be determined by measuring the pressure difference across an OA inlet system using the pressure taps provided. Because accurate field based measurements of OA flow- pressure drop relationship may be impractical, we assumed that in practice a user would estimate OA flow rates from the measured pressure drops and the pressure drop-velocity data provided by louver and bird-screen manufacturers. We recognize that the manufacturer's data on pressure drops across louvers and bird screens is not perfect and that data for many louver sizes are based on an extrapolation from data taken with another size of louver. However, our goal was to evaluate this practical approach that does not require an accurate a field-based measurement of OA flow rates.

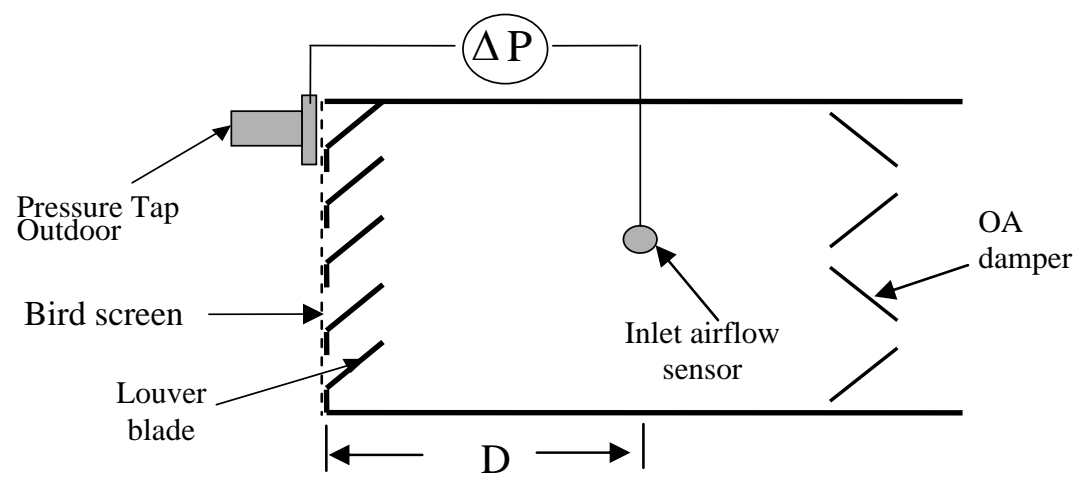

Figure 2. Schematic illustration of MT3. See the text for distance D.

Measurement technology number 4 (MT4), illustrated in Figure 3, contains an airflow straightener upstream of a set of six airflow monitoring blades, followed by a section of straight ductwork and then an OA damper. The airflow straightener is constructed of $3 / 8$ in $(0.95 \mathrm{~cm})$ aluminum honeycomb. The airflow monitoring blades are similar ${ }^{3}$ to those used in MT1. The basic measurement concept appears to be to straighten and condition the airflow with the airflow straightener, determine an average velocity from a pressure signal obtained from the airflow monitoring blades, and provide some straight duct downstream of the airflow monitoring blades to isolate the blades from airflow disturbances at the OA damper. The manufacturers recommended velocity range is 400 to $5000 \mathrm{fpm}$ (2 to $25 \mathrm{~m} / \mathrm{s}$ ) which corresponds to 1600 to $20,000 \mathrm{cfm}(760$ to $9,400 \mathrm{~L} / \mathrm{s})$ for a $2 \mathrm{ft}$ by $2 \mathrm{ft}(0.6 \mathrm{~m}$ by $0.6 \mathrm{~m})$ duct. The rated accuracy is $\pm 3 \%$ for a set of standard test conditions that include an upstream section of straight duct. In our tests, the unit was installed 8 in $(20 \mathrm{~cm})$ downstream the two OA intake louvers described subsequently.

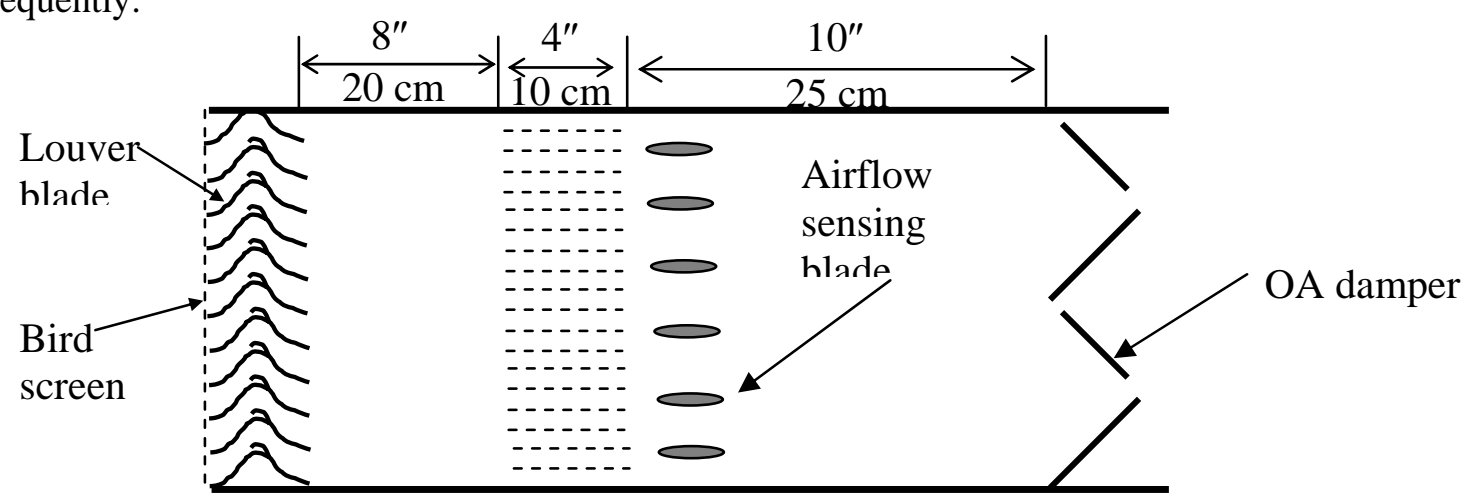

Figure 3. Schematic illustration of MT4 installed in the OA inlet section of a HVAC system.

\footnotetext{
${ }^{3}$ The same manufacturer produces MT1 and MT4.
} 


\section{Louvers used During Field Studies}

The evaluations of MT3 and MT4 took place using two different types of louvers at the OA inlet. Figure 4 illustrates a cross section of a part of each louver and Table 1 summarizes characteristics of the louvers, including the maximum recommended air velocities and the corresponding air flow rates for a nominal $2 \mathrm{ft}$ by $2 \mathrm{ft}(0.6 \mathrm{~m}$ by $0.6 \mathrm{~m})$ louver. The table also provides the air velocities and flow rates at $20 \%$ of the maximum recommendations. These numbers indicate the minimum velocities and flow rates expected in an HVAC system with an economizer that has a minimum OA flow rate equally to $20 \%$ of the maximum flow rate. Smoke studies indicate that air exits Louver 1 with a direction aligned predominately with the axis of the downstream ductwork while air exits Louver 3 with a substantial upward velocity component.
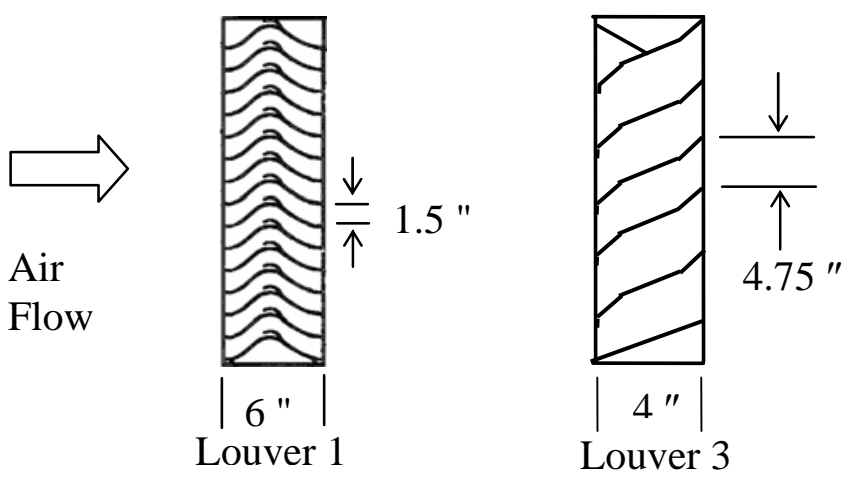

Figure 4. Simplified schematic illustration of cross sections of the louvers used during tests with Louver 1 viewed from the top and Louver 3 are viewed from the side. The actual louvers have more blades than shown in the drawings.

Table 1. Characteristics of the louvers

\begin{tabular}{|l|c|c|}
\hline Parameter & Louver 1 & Louver 3 \\
\hline Free area of louver $\mathrm{ft}^{2}\left(\mathrm{~m}^{2}\right)$ & $1.24(0.115)$ & $1.75(0.163)$ \\
\hline Maximum recommended free area velocity fpm (m/s) & $1856(9.43)$ & $696(3.54)$ \\
\hline Flow rate at maximum free area velocity cfm (L/s) & $2301(1086)$ & $1218(575)$ \\
\hline Maximum velocity upstream of louver fpm (m/s) & $575(2.92)$ & $305(1.55)$ \\
\hline Flow rate at 20\% of maximum recommended cfm (L/s) & $460(217)$ & $244(115)$ \\
\hline $\begin{array}{l}\text { Velocity upstream and downstream of louver at 20\% of } \\
\text { maximum recommended flow rate fpm (m/s) }\end{array}$ & $115(0.58)$ & $61(0.31)$ \\
\hline
\end{tabular}

\section{Evaluation methods}

The accuracy of OA flow rate measurements were assessed with each MT installed at the OA inlet section of a small HVAC system with a rated maximum supply air flow rate of $2400 \mathrm{cfm}(1130 \mathrm{~L} / \mathrm{s})$. Outdoor air was drawn into the HVAC system through a bird screen and intake louver installed approximately $17 \mathrm{ft}(5 \mathrm{~m})$ above grade level in the exterior wall of a building. If one could look through the intake louver from inside the OA duct, they would be looking at an angle of $220^{\circ}$ from north (i.e., looking SW). We were fortunate to have the space and permission needed to modify the outdoor air duct system as needed for accurate reference measurements of outdoor air flow rates using one or both of a set 
of two precision flow meters installed in parallel. The HVAC system had $6.2 \mathrm{ft}$ (1.9 m) of straight OA duct downstream of the OA intake louver where MTs could be installed. For our research, this OA duct split into two parallel $1.5 \mathrm{ft}(0.46 \mathrm{~m})$ diameter ducts each leading to an identical precision reference air flow meter. Downstream of the reference flow meters, the two parallel ducts fed into a single $2 \mathrm{ft}$ by $2 \mathrm{ft}$ $(0.61 \mathrm{~m}$ by $0.61 \mathrm{~m})$ duct which connected to the air handler. There was $2.5 \mathrm{ft}(0.76 \mathrm{~m})$ of straight duct upstream of the reference flow meters and $6 \mathrm{ft}(1.8 \mathrm{~m})$ of straight duct downstream of the flow meters, which exceeds the installation requirements of the manufacturer of the flow meters.

Our evaluation of the MTs depends on having minimal air leakage between the location of the MTs and the reference flow meters. All ductwork between these two locations was readily accessible and all joints and seams in ducts were sealed with a silicone sealant. The system was leak tested with the range of pressures encountered in practice and the leakage flow rate was $0.4 \%$ or less of the outdoor air flow rate.

The 18” $(46 \mathrm{~cm})$ nominal diameter reference flow meters have a flow straightener and converging nozzle, with set of Pitot-static type sensors centered at outlet of nozzle. These flow meters have a published range of 690 to $3700 \mathrm{cfm}$ ( 0.33 to $1.75 \mathrm{~m}^{3} \mathrm{~s}^{-1}$ ) with pressure signal of 0.4 to 1.2 inch water (10 to $290 \mathrm{~Pa}$ ). The manufacturer's rated accuracy is $\pm 0.5 \%$. For tests with the highest OA flow rates, we used two reference flow meters installed in parallel, because the pressure drop associated with using a single flow meter would have prevented us from achieving the target flow rates.

A multi-channel research grade electronic pressure transducer with automatic zero corrections was used to measure the pressure signals from the reference flow meters and from the MTs. This pressure transducer has a range of \pm 1.6 inch water ( $\pm 400 \mathrm{~Pa}$ ). The manufacturer's rated accuracy is the larger of \pm 0.001 inch water $( \pm 0.2 \mathrm{~Pa})$ or $\pm 1 \%$ of reading. The calibration of these transducers was checked using a micro-manometer that has a micrometer and electrical circuit for precisely measuring the height of the fluid column. A skilled user of the micro-manometer can obtain measurements repeatable within 0.0005 inch water $(0.1 \mathrm{~Pa})$. Based on the calibration data, the slope of the calibration curves changed less than $1 \%$ over the five-month period of monitoring. Due to calibration uncertainties, we estimate that the pressure measurement uncertainty in practice was approximately \pm 0.004 IWG $( \pm 1 \mathrm{~Pa}$ ) or less.

In practice, users of the MTs are likely to use less expensive and less accurate pressure transducers. Therefore, we also measured the pressure signals from the MTs with a selection of seven commercial pressure transducers, typical of the more accurate pressure sensor used with HVAC systems. To match the expected normal practice, we used these transducers with the factory calibrations. The characteristics of these pressure transducers are summarized in Table 2.

Air temperatures were measured upstream of both the reference flow meters and MTs. The temperature measurement system used precision thermistors as sensors with a rated accuracy of $\pm 0.45^{\circ} \mathrm{F}$ $\left( \pm 0.25^{\circ} \mathrm{C}\right)$.

Wind speed and wind direction were monitored $66 \mathrm{ft}(20 \mathrm{~m})$ above grade at a wind tower located approximately $1600 \mathrm{ft}(500 \mathrm{~m})$ from the field site. The accuracy ratings are $\pm 0.56 \mathrm{mph}+5 \%$ for wind speed and $\pm 5^{\circ}$ for wind direction. The system is audited twice annually and recalibrated when accuracy is outside of specifications

Pressure and temperature data were recorded every 2 minute on digital computers, wind speed at the OA intake was recorded every minute, and wind speed and direction data at the wind tower site were available only every 15 minute; thus, most of the results presented in this paper are based on 15 minute averages of measured data.

Data were collected with two to four nominal OA flow rates per technology. After setting each nominal OA flow rate by adjusting the opening of the OA damper and other HVAC system dampers, while always maintaining at least a pressure drop of at least $0.04 \mathrm{in}$. of water (10 Pa) across the damper. Data were collected for one to three weeks while wind speed and direction varied naturally.

The accuracy of the OA measurement technology being tested was determined by comparison to the reference airflow meter, and the percentage measurement error (\%error) was calculated from the following equation: 
LBNL 58856

$$
\% \text { error }=100 \%\left(Q_{m t}-Q_{r e f}\right) / Q_{r e f}
$$

where $Q_{m t}$ and $Q_{\text {ref }}$ are the OA flow rates from the measurement technology being evaluated and the reference flow meter, respectively.

Flow rates were calculated from the measured pressure signals using the calibration factors provided by the manufacturer. Following manufacturer's instructions, small corrections were made to account for differences between the actual air density during measurements and the density assumed for the manufacturer's calibration factors.

Table 2. Specifications of pressure transducers.

\begin{tabular}{|c|c|c|}
\hline $\begin{array}{c}\text { Pressure } \\
\text { Transducer ID. }\end{array}$ & $\begin{array}{c}\text { Pressure range } \\
\text { in. of water (Pa) }\end{array}$ & Rated accuracy \\
\hline Reference & $\pm 1.6( \pm 400)$ & $\begin{array}{c} \pm 0.001 \text { in. of water } \\
\pm 0.2 \text { Pa }) \text { or } \pm 1 \% \\
\text { or reading }\end{array}$ \\
\hline P1 & $0-0.25(0-62)$ & $1 \%$ of full scale \\
\hline P2 & $0-0.10(0-25)$ & $1 \%$ of full scale \\
\hline P3 & $0-0.10(0-25)$ & $0.25 \%$ of full scale \\
\hline P4 & $0-0.25(0-62)$ & $1 \%$ of full scale \\
\hline P5 & $0-0.10(0-25)$ & $1 \%$ of full scale \\
\hline P6 & $0-0.20(0-50)$ & $1 \%$ of full scale \\
\hline P7 & $0-0.10(0-25)$ & $1 \%$ of full scale \\
\hline
\end{tabular}

\section{RESULTS}

\section{Influence of wind speed on MT accuracy}

For the entire series of measurements, the fifteen-minute average wind speeds ranged from 0 to 19 mph (0 - $30.6 \mathrm{~km} / \mathrm{hr})$. However, the maximum wind speeds varied among the study configurations and maximum winds speeds were only $7.5 \mathrm{mph}(12 \mathrm{~km} / \mathrm{hr})$ in one of the studies of MT3 and MT4.

Figure 5 provides an example plot indicating how the accuracy of MT1, when operated with an OA flow rate of $1000 \mathrm{cfm}(472 \mathrm{~L} / \mathrm{s})$, varied with wind speed. There is no indication of an important or significant relationship between measurement error and wind speed, i.e., error decreases by $0.02 \%$ per 1 $\mathrm{mph}(0.01 \%$ per $1 \mathrm{~km} / \mathrm{hr})$ increase in wind speed. The square of the Pearson correlation coefficient between error and wind speed is only 0.008 ; thus, only $0.8 \%$ of the variance in error is explained by changes in wind speed.

We anticipated that MT3 would be most sensitive to winds because it relies on an outdoor static pressure tap. Figure 6 shows an example of the error of MT3 plotted versus wind speed. The impact of wind speed on error is small, i.e., in this set of data the error increases $0.11 \%$ per each $1 \mathrm{mph}(0.07 \%$ per $1 \mathrm{~km} / \mathrm{hr}$ ) increase in wind speed and only $14 \%$ of the variance in error is explained by changes in wind speed. 
LBNL 58856

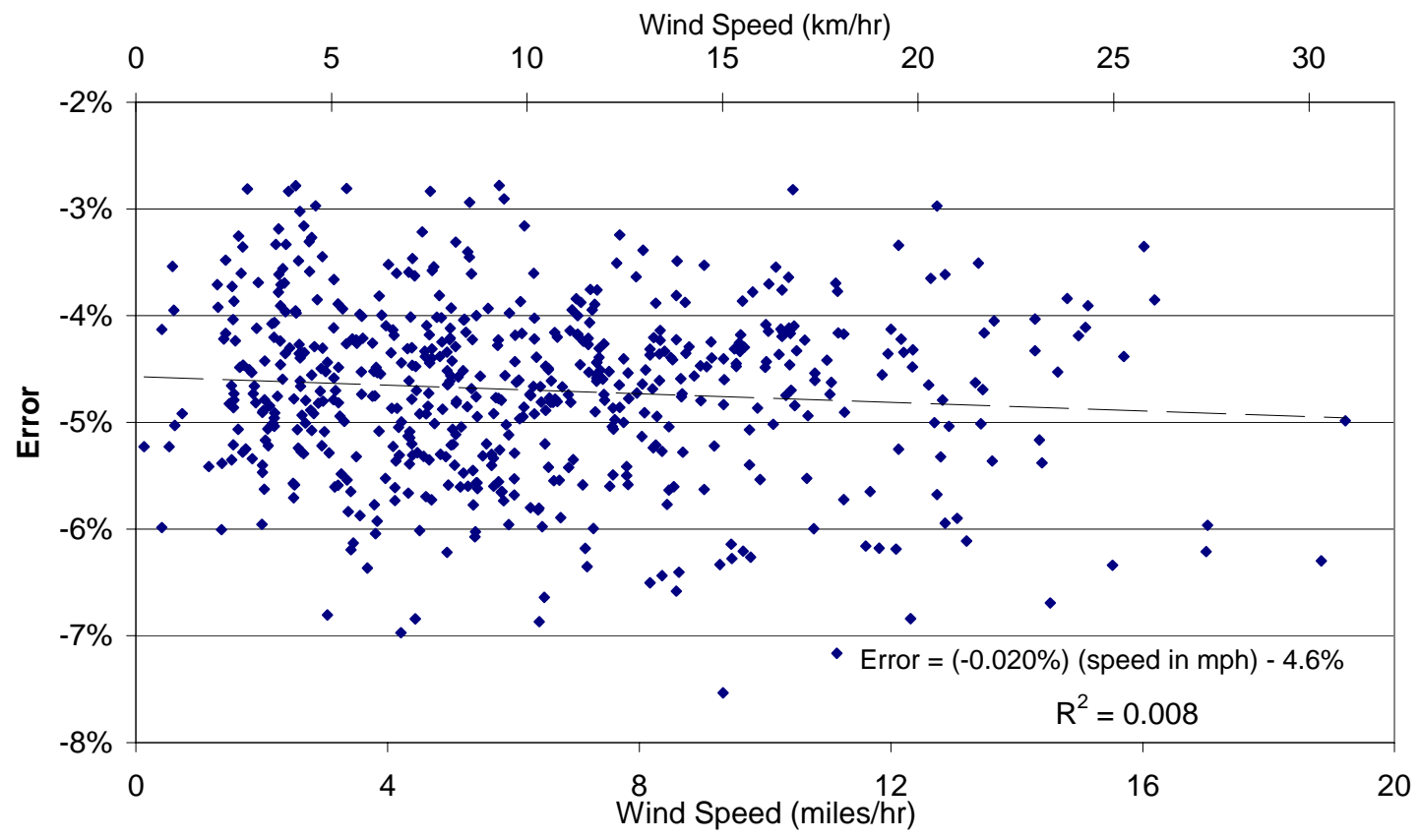

Figure 5. Measurement error versus wind speed from tests with MT 1 and an OA flow rate of $1000 \mathrm{cfm}$ (472 L/s).

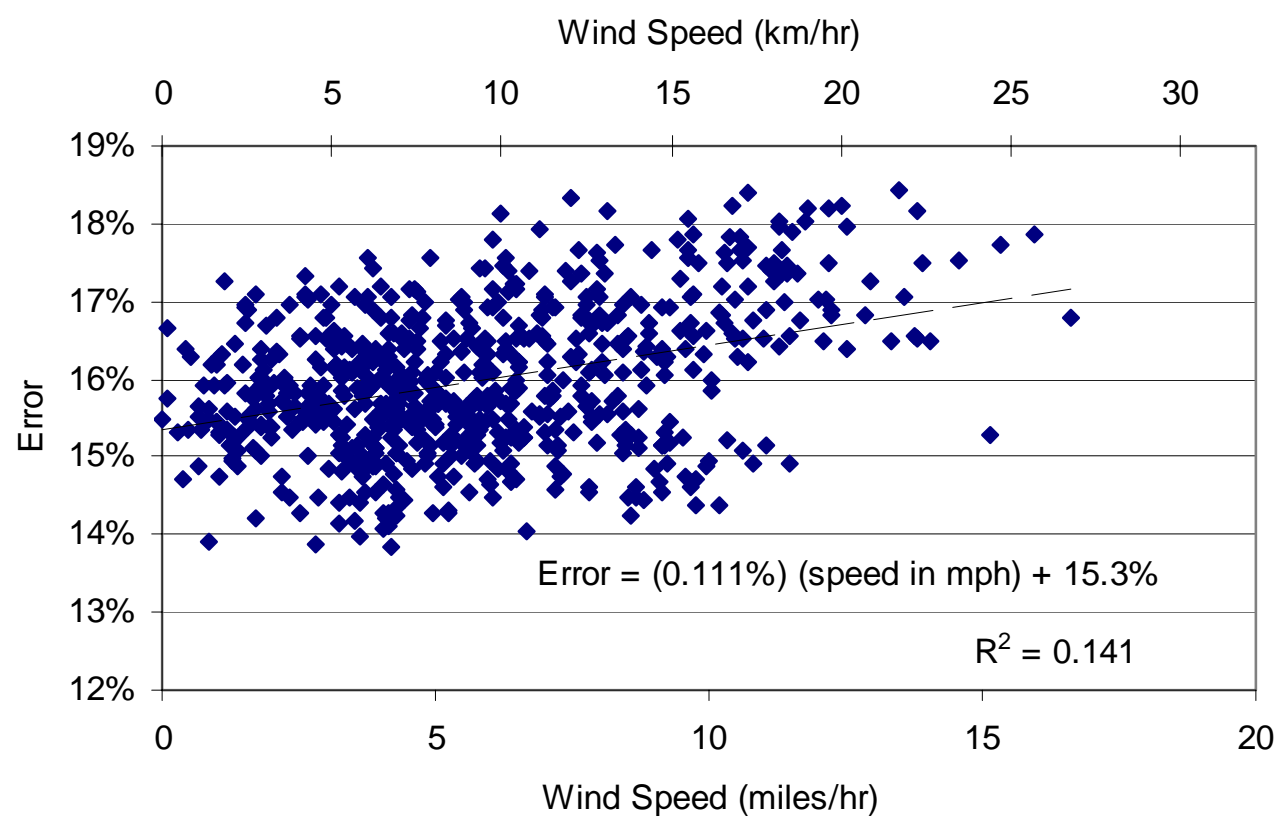

Figure 6. Measurement error versus wind speed from tests with MT3 with Louver 3 and an OA flow rate of $1800 \mathrm{cfm}(850 \mathrm{~L} / \mathrm{s})$.

Similar data were collected at multiple OA flow rates for all three MTs and Table 3 summarizes slopes and correlation coefficients for the error-wind speed relationships. The slopes represent the percentage point change in error per $1 \mathrm{mph}[1 \mathrm{~km} / \mathrm{hr}]$ increase in wind speed from a linear fit to the data. For example, a slope of $1.0 \%$ per mph would indicate a one percentage point increase in error for a $1 \mathrm{mph}$ 
increase in wind speed. In all test configurations except one, the slope was less than $0.38 \%$ per mph [0.24\% per $\mathrm{km} / \mathrm{hr}]$; hence, wind speed did not normally affect accuracy to a significant extent. In one set of tests with MT4, the slope was as high as $1.2 \%$ per mph $(0.76 \%$ per $\mathrm{km} / \mathrm{hr})$ with an $\mathrm{R}^{2}$ of 0.40 . This trend may be largely coincidental because wind speed had little influence on the accuracy of MT4 under other test conditions, and even in this case the data indicated no impact of wind speed on errors for wind speeds exceeding $5 \mathrm{mph}(8 \mathrm{~km} / \mathrm{hr})$.

Table 3. Results of linear least square fitting of measurement error versus wind speed and wind direction.

\begin{tabular}{|c|c|c|c|c|c|c|c|c|c|}
\hline & & \multicolumn{4}{|c|}{ Error vs. Wind Speed } & \multicolumn{4}{|c|}{ Error vs. Wind Direction } \\
\hline & & \multicolumn{2}{|c|}{ Louver 1} & \multicolumn{2}{|c|}{ Louver 3} & \multicolumn{2}{|c|}{ Louver 1} & \multicolumn{2}{|c|}{ Louver 3} \\
\hline MT & $\begin{array}{l}\text { Flow Rate } \\
\text { cfm (L/s) }\end{array}$ & $\begin{array}{c}\text { Slope } \\
\% \text { / mph } \\
{[\% /(\mathrm{km} / \mathrm{hr})]}\end{array}$ & $\mathrm{R}^{2}$ & $\begin{array}{c}\text { Slope } \\
\% / \mathrm{mph} \\
{[\% /(\mathrm{km} / \mathrm{hr})]}\end{array}$ & $\mathrm{R}^{2}$ & $\begin{array}{c}\text { Slope } \\
\% \text { / } 10 \\
\text { degrees }\end{array}$ & $\mathrm{R}^{2}$ & $\begin{array}{c}\text { Slope } \\
\% \text { / } 10 \\
\text { degrees }\end{array}$ & $\mathrm{R}^{2}$ \\
\hline 1 & $750(350)$ & $-0.04[-0.02]$ & $*$ & ----------- & ---- & -0.02 & 0.02 & ----------- & ---- \\
\hline 1 & $1000(470)$ & $-0.02[-0.01]$ & $*$ & --------- & ---- & 0.01 & $*$ & --------- & ---- \\
\hline 1 & $1500(710)$ & $0.02[0.01]$ & $*$ & ---------- & ---- & 0.01 & $*$ & ---------- & ---- \\
\hline 1 & $2000(940)$ & $-0.01[-0.01]$ & $*$ & ----------- & 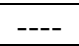 & $*$ & $*$ & ----------- & ---- \\
\hline 3 & $1000(470)$ & $-0.22[-0.14]$ & 0.05 & ---------- & ---- & -0.09 & 0.20 & ---------- & $\begin{array}{ll}--- \\
-\end{array}$ \\
\hline 3 & $1500(710)$ & ---------- & ---- & $0.08[0.05]$ & 0.05 & ----------- & & 0.01 & $*$ \\
\hline 3 & $1600(760)$ & $-0.18[-0.11]$ & 0.07 & $0.36[0.22]$ & 0.13 & -0.05 & 0.11 & $*$ & $*$ \\
\hline 3 & $1800(850)$ & ---------- & & $0.11[0.07]$ & 0.14 & ----------- & & 0.04 & 0.09 \\
\hline 3 & $2000(940)$ & $-0.24[-0.15]$ & 0.15 & ----------- & ---- & -0.02 & 0.03 & & \\
\hline 4 & $1500(710)$ & ---------- & & $0.37[0.23]$ & 0.24 & ---------- & & 0.05 & 0.02 \\
\hline 4 & $1600(760)$ & $0.32[0.20]$ & 0.23 & $1.22[0.76]$ & 0.40 & 0.05 & 0.14 & 0.17 & 0.06 \\
\hline 4 & $1800(850)$ & ----------- & & $0.20[0.12]$ & 0.12 & ----------- & ---- & 0.01 & $*$ \\
\hline 4 & $2000(940)$ & $0.02[0.01]$ & $*$ & ----------- & ---- & 0.02 & 0.05 & ----------- & $\begin{array}{l}--- \\
\end{array}$ \\
\hline
\end{tabular}

* Absolute value less than 0.01

\section{Influence of wind direction on MT accuracy}

Wind directions varied over the full $360^{\circ}$ range with substantial data collected and all wind directions. However, a disproportionate fraction of the time the wind direction was centered in $\mathrm{a} \pm 20^{\circ}$ band around $300^{\circ}$, i.e., the predominant wind direction was WNW.

Figure 7 provides an example plot of measurement error versus wind direction. In this example plot, no significant influence of wind direction on error is evident. In fact, via an examination of the slopes in Table 3 it is apparent that in no case did wind direction significantly affect measurement error. 
LBNL 58856

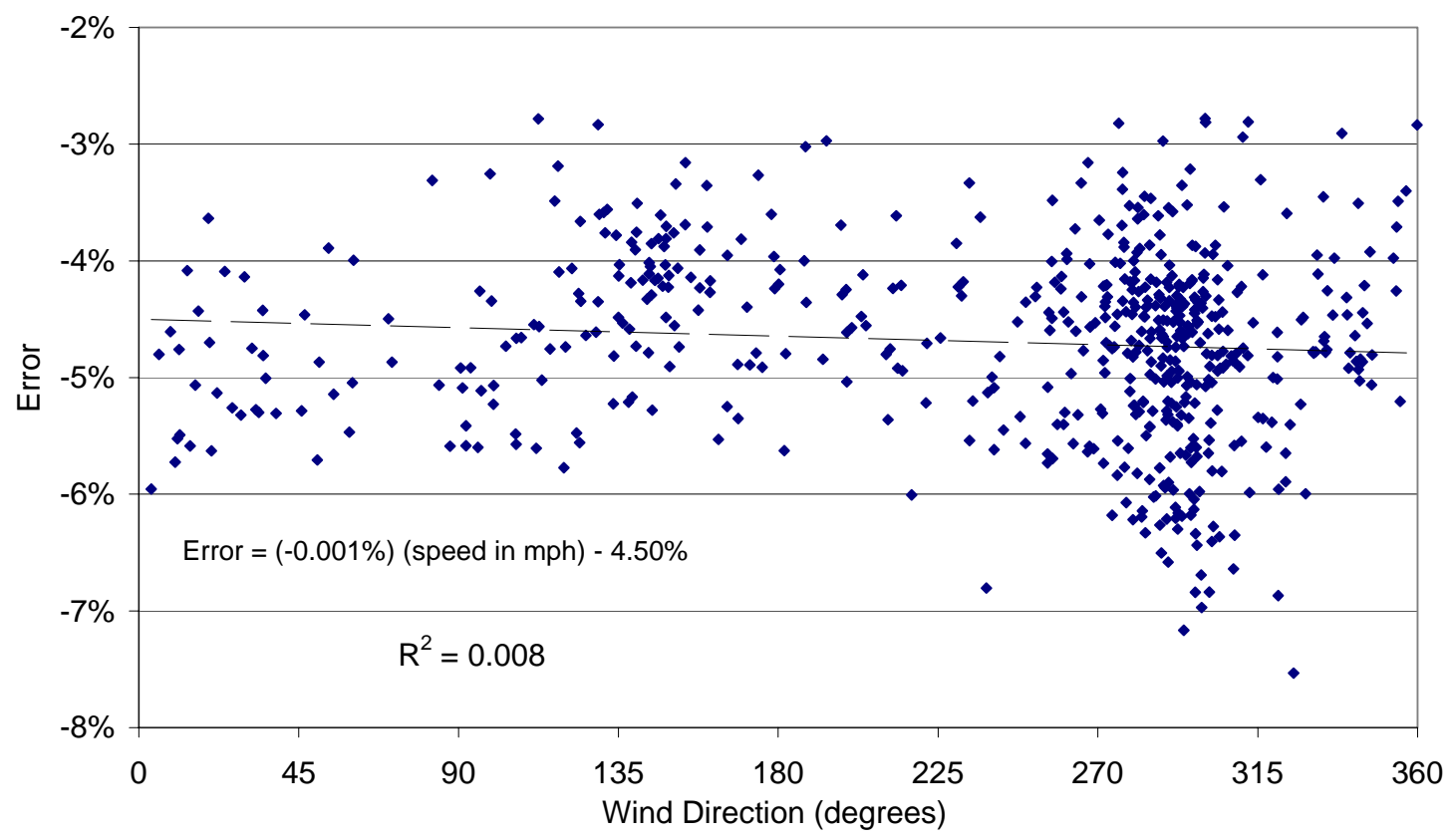

Figure 7. Example plot illustrating that measurement error of MT1 was unaffected by wind directions. The plot is for MT1 with an outdoor air flow rate of $1000 \mathrm{cfm}(472 \mathrm{~L} / \mathrm{s})$.

\section{$\underline{\text { Accuracy of Measurements of Outdoor Air Flow Rates }}$}

Figure 8 provides summary data on the accuracy of measuring outdoor air flow rates when the research-grade pressure transducer was used to measure pressure signals. For reference, the mean measurement error from prior laboratory tests (Fisk et al 2005a) of the same technologies is also plotted. In the field study, the errors of MT1 were $-2 \%$ to $-5 \%$. In the prior laboratory tests of MT1, the average error was $-2.5 \%$ at the flow rates used in the field study. MT3, used with Louver 1 , had an error of approximately $+33 \%$ to $+36 \%$ in the field study, compared to $+22 \%$ in the prior lab studies. When MT3 was used with L3, the error was approximately $+12 \%$ to $+16 \%$, which compares to $+20 \%$ in the laboratory study. MT4, when used with L1, had an error of approximately $-16 \%$ in this field study, compared to $+2 \%$ in the prior laboratory study. For this latter case of MT 4 , the comparison to laboratory data is clearly imperfect, because in the laboratory study the upstream louver had been modified. For the other cases, there is a fair to good correspondence between errors indicated in this field study and prior errors determined in the laboratory.

In Figure 8, we did not plot the results of tests of MT4 in conjunction with L3, as the errors have a very different magnitude and we have no prior laboratory data for comparison. The mean errors were $109 \%, 105 \%$, and $133 \%$, with standard deviations of only $2 \%$ to $4 \%$, for the flow rates of 1500,1600 , and $1800 \mathrm{cfm}(710,760$, and $850 \mathrm{~L} / \mathrm{s})$. We suspected that the large errors were due to very uneven airflow through the airflow sensing blades of MT4, caused by the strong upward trajectory of air as it exits L3. Independent measurement of the pressure signals from the six horizontal airflow sensing blades of MT4 supported this hypothesis. 
LBNL 58856

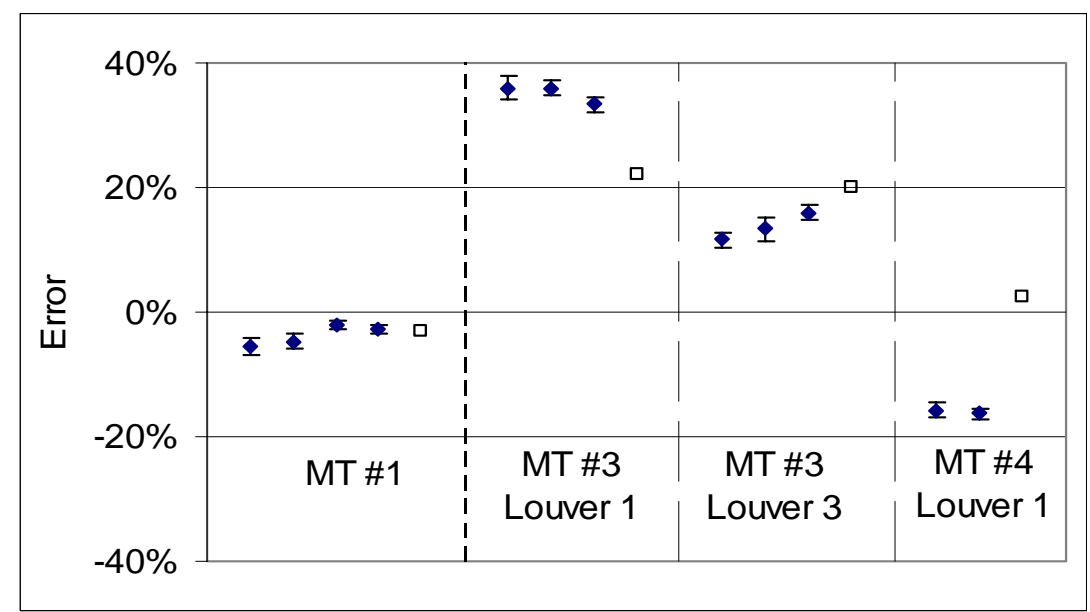

Figure 8. Measurement errors from the field studies and corresponding errors measured in prior laboratory studies. The solid data points represent field study data with increasing outdoor air flow rates from left to right (see flow rates in Table 3). The error bars represent plus and minus one standard deviation. The open square data points represent average errors determined in a prior laboratory study from tests of the same MTs with a corresponding range of outdoor air flow rates.

\section{Accuracy of Commercial Pressure Transducers and Implications for OA Flow Measurements}

Table 4 shows the mean and standard deviation of errors in pressure measurement errors with transducers P1 - P7. The numbers shown assume that our calibrated research-grade pressure transducer with auto zeroing has no error. Since, in fact, the research grade transducer is imperfect, indications of error less than a few percent are probably not meaningful. The last row of the table provides the maximum expected error of each transducer based on the manufacturers error specification and the maximum pressure actually measured with that transducer. When reviewing these data, the reader should keep in mind that the pressure transducers were used without calibration-based corrections because we believe that many facility managers and commissioning agents would not have tools suitable for calibrating transducers at such low pressures.

From a review of Table 4, it is apparent that transducers P1 and P6 essentially matched our research grade transducer in accuracy. P2, and P3, were accurate within $11 \%$ for measured pressures of 0.028 IWG (7 Pa) or larger but less than 0.1 IWG. P5 had the largest errors, although these were due substantially to a large offset at zero pressure that may have been corrected via a zeroing of the transducer. Transducers P4 and P5 sometimes had a noisy signal which is indicated by the large standard deviations in error.

To quantify how these errors in pressure measurements will affect the accuracy of measuring OA flow rates, we note that to a good first approximation, with the measurement technologies discussed in this paper, the OA flow rates are proportional to the square root of the measured pressure differences. Consequently, the percentage error in flow rate will be smaller than the percentage error in the pressure measurement, as shown in Figure 9. Combining the numbers in Table 4 and the plot in Figure 9, we can estimate that the use of transducers P1 or P6 would not significantly increase the errors in measurement of OA flow rates. The use of P2, P3, and P7 could increase (or decrease) measurement errors by 5 to 10 percentage points above that indicated in Figure 9, while the use of P5 (without correction for the zero offset) could result in very large incremental errors in OA flow rates. 
Table 4. Mean (standard deviation) in pressure transducer error if one assumes that our calibrated research grade transducer has no error. The numbers are expressed as the percent of the reference pressure.

\begin{tabular}{|c|c|c|c|c|c|c|c|}
\hline $\begin{array}{c}\text { Pressure } \\
\text { IWG (Pa) }\end{array}$ & \multicolumn{1}{|c|}{ P1 } & \multicolumn{1}{|c|}{ P2 } & \multicolumn{1}{c|}{ P4 } & P5 & P6 & P7 \\
\hline $0.024(6)$ & $0 \%(1 \%)$ & $11 \%(1 \%)$ & $\begin{array}{l}-16 \% \\
(1 \%)\end{array}$ & $0 \%(7 \%)$ & $-63 \%(24 \%)$ & $-4 \%(3 \%)$ & $19 \%(4 \%)$ \\
\hline $0.028(7)$ & $3 \%(1 \%)$ & $7 \%(1 \%)$ & $1 \%(1 \%)$ & $9 \%(3 \%)$ & $-49 \%(11 \%)$ & $4 \%(1 \%)$ & $7 \%(2 \%)$ \\
\hline $0.032(8)$ & $1 \%(1 \%$ & $8 \%(1 \%)$ & $-11 \%(1 \%)$ & $3 \%(4 \%)$ & $-33 \%(14 \%)$ & $-2 \%(2 \%)$ & $16 \%(3 \%)$ \\
\hline $0.048(12)$ & $3 \%(1 \%)$ & $4 \%(1 \%)$ & $1 \%(0 \%)$ & $7 \%(1 \%)$ & $-26 \%(7 \%)$ & $4 \%(1 \%)$ & $4 \%(2 \%)$ \\
\hline $0.100(25)$ & $1 \%(0 \%)$ & ---- & ---- & $-31 \%(26 \%)$ & ---- & $2 \%(1 \%)$ & ----- \\
\hline $0.176(44)$ & $1 \%(0 \%)$ & ----- & ---- & $-60 \%(1 \%)$ & ---- & $1 \%(1 \%)$ & ---- \\
\hline $0.184(46)$ & $0 \%(0 \%)$ & ---- & ---- & $-61 \%(6 \%)$ & ---- & $2 \%(1 \%)$ & --- \\
\hline $\begin{array}{c}\text { Max. Expected } \\
\text { Error } \\
\text { \% of reading) }\end{array}$ & $1.3 \%$ & $2.1 \%$ & $0.5 \%$ & $1.3 \%$ & $2.1 \%$ & $1.1 \%$ & $2.1 \%$ \\
\hline
\end{tabular}

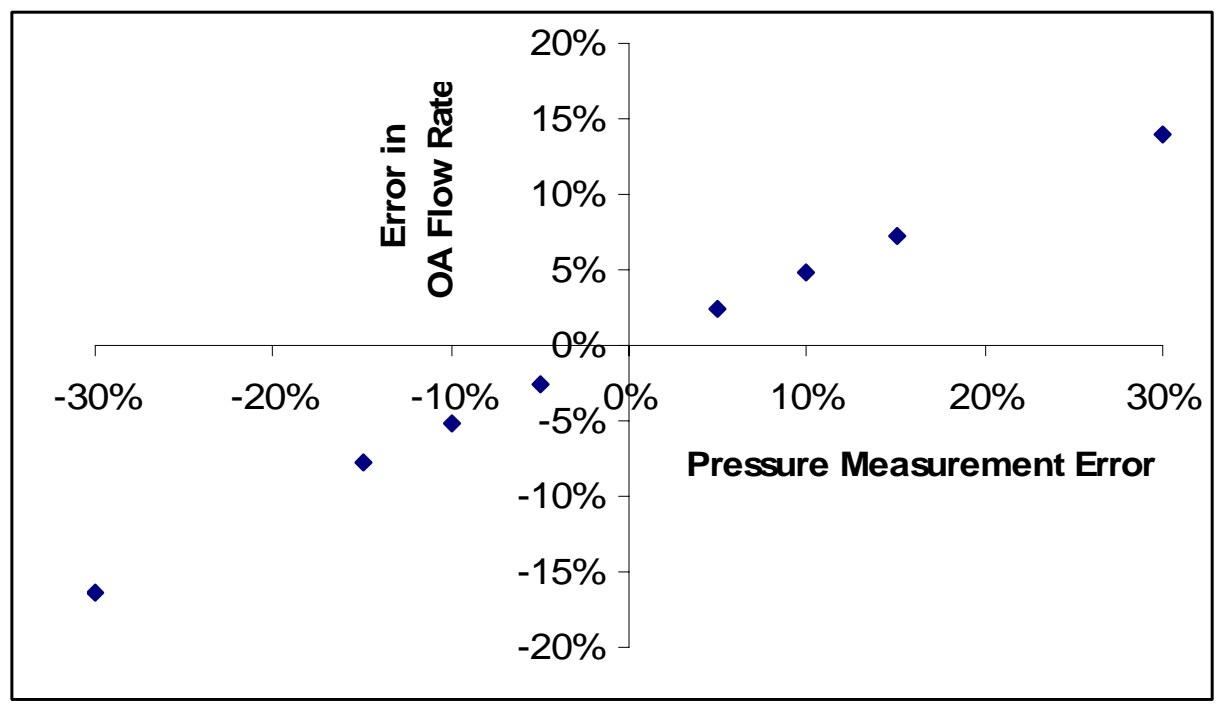

Figure 9. Illustration of how pressure measurement error affects the accuracy of measurements of OA flow rates.

\section{DISCUSSION}

The main goal of these field studies were to determine if the accuracy of measurements of outdoor air flow rates into air handlers was substantially degraded by winds. For the technologies evaluated and range of wind speeds encountered, the answer is clear -neither wind speed or wind direction have an important impact on measurement accuracy. The maximum winds speeds in this study [19 mph (30.6 $\mathrm{km} / \mathrm{hr}$ )] were moderate; thus, we cannot rule out the possibility that particularly high wind speeds cause large errors. For reference, we selected wind speed data in 17 large U.S. cities. The wind speed that was exceeded only $5 \%$ of the time in these cities ranged from 13.0 to $21.6 \mathrm{mph}$ and averaged $18.5 \mathrm{mph}$ (20.9 to $34.7 \mathrm{~km} / \mathrm{hr}$, average $29.8 \mathrm{~km} / \mathrm{hr}$ ); thus, winds during ours studies were modestly lower than winds encountered fairly commonly in U.S. cities.

The field study confirmed the that these three measurement technologies can provide reasonable accurate measurements of outdoor air intake rates in field settings, if the pressure signals are measured with high accuracy. This statement assumes that measured flow rates with errors on the order of $20 \%$, and possibly even with errors as high as $30 \%$, will be judged acceptable given the current lack of any 
measurement system in most buildings. The field study also confirmed that the utility of the much more quickly performed laboratory studies of measurement accuracy because the errors measured in the field and the laboratory were normally within approximately 10 percentage points. (The $20 \%$ deviation for MT4 with L1 may be a consequence of the modification made to L1 before conducting the laboratory studies, whereas the version of L1 used in the field study was unmodified).

The field study confirmed our prior speculation (Fisk et al 2005a) that MT4 might be less accurate with an upstream intake louver that causes the outlet air to be strongly directed toward a duct wall - a very common situation. In the present case, MT4 combined with L3, the errors exceeded $100 \%$.

Among the three technologies evaluated, MT1 was the most accurate. An advantage of MT1 is that it integrates the upstream louver, which has a large impact on the airflow profile, with the airflow sensors. In contrast, the airflow profiles through the sensors of MT3 and MT4 will depend on the type of upstream louver utilized and on the relative position of the louver and sensors. Consequently, the factory calibration of MT1 should apply in practice, as long as downstream components do not substantially perturb the flow profile through MT1. In contrast, the calibration of MT3 and MT4 will vary somewhat depending on installation details.

The study found that the accuracy of commercial pressure transducers varied widely. Within our ability to test them, two commercial pressure transducers were as accurate as our much more expensive research grade transducer. At the other extreme, one transducer had more than a $60 \%$ error with the lowest pressure signal, although a simple correction or adjustment for the reading at zero pressure may have eliminated most of this error. We tracked pressure transducer performance only for a five-month period; hence, we do not know how transducers will perform years after they are purchased and installed.

Most importantly, the study shows that reasonably accurate measurements of OA flow rates are possible in field settings. Given the significant impact of OA flow rates on both energy use and occupant health, more widespread use of technologies that provide for real time measurements of OA flow rates seems warranted. Our prior papers (Fisk et al 2005a, 2005b) provide additional guidance on the selection and utilization of these technologies.

\section{CONCLUSIONS}

- For the technologies evaluated and range of wind speeds encountered, neither wind speed or wind direction had an important impact on the accuracy of measurements of outdoor air flow rates into HVAC systems.

- The study found that the accuracy of commercial pressure transducers, marketed for use in HVAC systems, varied widely. The accuracy of some of these transducers was sufficient for use with technologies designed to measure rates of outdoor airflow into HVAC systems.

- Most importantly, the study shows that reasonably accurate measurements of OA flow rates are possible in field settings.

\section{ACKNOWLEDGEMENTS}

This work was supported by the assistant Secretary for Energy Efficiency and Renewable Energy, Building Technologies Program of the U.S. Department of Energy under contract DE-AC02-05CH11231. The authors thank Terry Logee of DOE for program management and Steve Taylor and Peng Xu for their reviews of a draft of the report on which this paper was based. 
LBNL 58856

\section{REFERENCES}

ASHRAE. 2004. ANSI/ASHRAE Standard 62.1-2004, Ventilation for acceptable indoor air quality. Atlanta: American Society of Heating, Refrigerating, and Air Conditioning Engineers, Inc.

ASHRAE. 1999. ANSI/ASHRAE Standard 62-1999, Ventilation for acceptable indoor air quality. Atlanta: American Society of Heating, Refrigerating, and Air Conditioning Engineers, Inc.

ASHRAE. 1999a. ANSI/ASHRAE Standard 120-1999 (1999), Method of testing to determine flow resistance of HVAC ducts and fittings. Atlanta: American Society of Heating, Refrigerating, and Air Conditioning Engineers, Inc.

Fisk WJ, Faulkner D, Sullivan D, Delp W. 2003. Outdoor airflow into HVAC systems: an evaluation of measurement technologies. LBNL-53834, Lawrence Berkeley National Laboratory Report, Berkeley, CA

Fisk WJ, Faulkner D, Sullivan D, Webster T (2004). An evaluation of technologies for real-time measurement of rates of outdoor airflow into HVAC systems. Lawrence Berkeley National Laboratory Report, Berkeley, CA. LBNL-56397.

Fisk WJ, Faulkner D, Sullivan DP (2005a) An evaluation of three commercially available technologies for real-time measurement of rates of outdoor airflow into HVAC systems. ASHRAE Transactions 111(2).

Fisk WJ, Faulkner D, Sullivan DP (2005b) Technologies for measuring flow rates of outdoor air into HVAC systems: some causes and suggested cures for measurement errors. ASHRAE Transactions 111(2). LBNL-56604

Kettler JP (1995) Minimum ventilation control for VAV systems: fan tracking versus workable solutions. ASHRAE Transactions 101(2): 625-630

Kettler J (2000) Measuring and controlling outdoor airflow. IAQ Applications, Winter 2000, Atlanta: American Society of Heating, Refrigerating, and Air Conditioning Engineers, Inc.

Krarti, M, Brandemuehi MJ, Schroeder C, Jeannette E. 1999. Techniques for measuring and controlling outside air intake rates in variable air volume systems. Final Report of ASHRAE Research Project RP-980, Atlanta: American Society of Heating, Refrigerating, and Air Conditioning Engineers, Inc.

Lagus Applied Technologies. 1995. Air change rates in non-residential buildings in California, Report P400-91-034BCN, Sacramento, CA: California Energy Commission.

Persily A. 1989. Ventilation rates in office buildings. Proceedings of the IAQ'89 Conference The Human Equation: Health and Comfort, pp. 128-136. Atlanta: American Society of Heating, Refrigerating, and Air Conditioning Engineers, Inc.

Persily A and Gorfain J. 2004. Analysis of office building ventilation data from the U.S., Environmental Protection Agency Building Assessment Survey and Evaluation (BASE) study. NISTIR-7145, National Institute of Standards and Technology, U.S. Department of Commerce.

Seppanen, O.A., Fisk, W.J., and Mendell, M.J. 1999. Association of ventilation rates and $\mathrm{CO}_{2}$ concentrations with health and other human responses in commercial and institutional buildings. Indoor Air 9, pp. 226-252.

Turk, B.H., Brown J.T., Geisling-Sobatka, K., Froelich, D.A., Grimsrud, D.T., Harrison, J., Koonce, J.F., Prill, R.J., and Revzan, K.L. 1987. Indoor air quality and ventilation measurements in 38 Pacific Northwest commercial Buildings--volume 1: measurement results and interpretation. Lawrence Berkeley Laboratory Report, LBL-22315 1/2, Berkeley, CA. 